\title{
Naming pictures at no cost: Asymmetries in picture and word conditional naming
}

\author{
REMO JOB and ELENA TENCONI \\ University of Padua, Padua, Italy
}

\begin{abstract}
We report a striking finding about naming and categorization of pictures and reading aloud and categorization of words. The categorization of a word before reading it aloud leads to an increase in response time as compared with the condition in which naming is not conditional on the categorization of the word. Quite differently, no cost is associated with the conditional naming of pictures. Results are discussed in terms of multiple procedures operating on pictorial and verbal stimuli to retrieve phonological forms.
\end{abstract}

The processes involved in naming and categorizing pictures and words have been extensively studied since they may shed light on a number of issues concerning the functional architecture of the mental system. Interesting asymmetries between naming and categorization both within and between the verbal and the pictorial modalities have been reported in the literature. Picture naming is slower than picture categorization (e.g., Lloyd-Jones \& Humphreys, 1997; Potter \& Faulconer, 1975), but word naming is faster than word categorization (e.g., Lotto, 1996). Also, words are named faster, but are usually categorized more slowly, than pictures (e.g., Job, Rumiati, \& Lotto, 1992; Snodgrass \& McCullough, 1986).

The interpretation of these asymmetries relies on the assumption that different procedures, and thus different kinds of representation, mediate task performance in the two modalities.

In this perspective, word categorization requires access to the semantic system, whereas word naming can be accomplished lexically, or even sublexically, without recourse to semantic information (McCann \& Besner, 1987; Morton \& Patterson, 1980). The former procedure is assumed to take longer because of the slower rate of activation of semantic representations as compared with phonological representations (Coltheart, 1985; Strain, Patterson, \& Seidenberg, 1995), and therefore word categorization is expected to take longer than word naming.

For pictures, naming requires access to the semantic system in order to retrieve the concept's lexical label, but so does categorization, in order to identify the semantic class the element belongs to (Lotto, Job, \& Rumiati, 1999). Thus, there is a large processing overlap between picture categorization and picture naming.

This research was supported in part by Grant COFIN from MURST. We thank Max Coltheart, Matti Laine, Lorella Lotto, and an anonymous reviewer for helpful comments on a first version of the manuscript. Correspondence concerning this article should be addressed to R. Job, DPSS, University of Padua, Via Venezia 8, 35100 Padua, Italy (e-mail: remojob@unipd.it).
In spite of such overlap, there are two reasons why picture categorization might be faster than picture naming. First, picture naming - unlike picture categorizationrequires retrieval of the picture name and hence accessing the name-retrieval stage. Second, the semantic representation needed for category decisions may be only partially activated (Rapp \& Caramazza, 1991), ${ }^{1}$ whereas full(er) activation at the semantic level is needed for correct naming to occur.

In this framework, in performing both the naming task and the categorization task on the same item, picture and word processing should be affected differently since in the former case the kinds of representation accessed for naming and categorization are largely overlapping, whereas in the latter case, different representations are involved. To explore this issue, we asked participants to name either pictures or words under two experimental conditions: a free-naming and a conditional-naming condition. In the former, the participants named each stimulus as it appeared on a screen. In the latter, they named a presented stimulus only when it belonged to a prespecified category. Thus, for target items, the participants had to perform a (covert) categorization task and an (overt) naming task.

On the basis of the claims reviewed above, we can predict a sizeable delay in response time in the condition in which the participants are asked to first categorize and then to name a word with respect to a condition in which naming is the only task required. This is to be expected if free naming is mediated by (any of) the assumedly faster nonsemantic procedures and conditional naming is mediated by the semantic system, whose activation is necessary for performing the categorization task. On the other hand, since picture categorization and naming both require the activation of the semantic level of representation, no delay in the conditional-naming condition should be expected.

In the conditional-naming condition, we can predict a cost associated with performing the two tasks jointly (Pashler, 1984), but this cost should be analogous for both words and pictures. The interesting issue, then, is to 
look for any specific, additional processing cost of the conditional-naming condition within each class of stimuli (pictures and words) that could be ascribed to differences in the procedures used in the two experimental conditions. These predictions were tested in the two experiments presented below.

\section{EXPERIMENT 1 Reading Words Aloud}

\section{Method}

Participants. Sixty students at the University of Padua took part in the study. All had normal or corrected-to-normal vision. Half were randomly assigned to the free-naming condition and half to the conditional-naming condition.

Material. The names of 48 pictures selected from the set standardized for Italian (Dell' Acqua, Lotto, \& Job, 2000) were used. Half referred to elements from biological categories and half to elements from categories of artifacts. Category membership ratings, as well as frequency (Bortolini, Tagliavini, \& Zampolli, 1974) and number of letters, were balanced across the biological and inanimate sets. The stimuli in the two sets were matched for their first letters. The set of artifacts were drawn from the categories of weapons, furniture, vehicles, and clothing, and the set of biological elements from the categories of fruits, vegetables, mammals, and birds.

Procedure. The participants were tested individually in a soundattenuated room. The experimenter was seated behind the participant to record errors and equipment failures. Presentation of the stimuli and recording of the responses were controlled by a Macintosh computer connected to a voice key. Each trial consisted of the following sequence of events: A fixation point appeared in the center of the screen for $400 \mathrm{msec}$. The word then appeared and stayed in view until either the participant produced the vocal response or $1,500 \mathrm{msec}$ had elapsed. After an interstimulus interval of $1,000 \mathrm{msec}$, the fixation point appeared again. Reaction time (RT) in milliseconds was automatically recorded from word onset. The 48 stimuli were presented in one of three different randomized orders with the constraint that no more than three items from a given set (biological or artifact) appeared in succession. The participants were instructed to name each word as distinctly and quickly as possible and to try to avoid producing irrelevant sounds that might trigger the voice key. Before the experimental session, 12 practice trials were used to familiarize the participants with the task and to control for the sensitivity of the voice key. The experimental session lasted about $10 \mathrm{~min}$. The participants were randomly assigned to one of the two conditions in the experiment.

In the conditional-naming condition, the participants were presented with the entire list of stimuli but were instructed to name only the words of a prespecified set. Specifically, half of the participants $(n=15)$ were asked to name the words referring to artifacts and to stay silent otherwise, whereas the other half $(n=15)$ were asked to name the words referring to biological elements and to stay silent otherwise. In the free-naming condition, the participants $(N=30)$ were asked to name all words. However, in order to have comparable groups in the two experimental conditions, 15 participants of the free-naming condition served as controls in the artifact conditional-naming task, and for them, only their responses to artifacts were considered. The other 15 participants in the free-naming condition served as controls in the biological conditional-naming task, and for them, only their performance on biological items was considered.

\section{Results and Discussion}

Data from 12 trials were omitted due to failures of the voice key. The effects of very long and very short latencies were reduced by trimming to the cutoff value of two standard deviations above or below the mean for each participant. Out of responses to 1,440 stimuli, $53(3.68 \%)$ were outliers.

Mean RTs of correct responses and percentages of errors are reported in Table 1.

RTs in the free-naming condition were significantly faster than the corresponding RTs in the conditionalnaming condition [by subjects, $t(58)=-11.25, p<.001$; by items, $t(47)=-26.22, p<.001]$.

As expected, when the participants had to classify the items in order to name them, their naming times were substantially longer than when they had only to name them. This pattern was expected on the assumption that word naming does not require access to the semantic system, whereas word categorization does.

This pattern can also be explained with reference to the dual- versus single-task paradigm, since in the conditionalnaming condition, the participants were presented with stimuli that they had first to categorize and then, eventually, to name. Even though Task 1 is unspeeded, this may lead to a delay in the performance of the second task (see Pashler, 1984).

If the pattern of results was due entirely to the use of a dual-task paradigm, we should obtain a comparable pattern with pictures. However, if picture and word processing differ along the lines that were discussed in the introduction, we might expect a different pattern for picture naming under the free- and conditional-naming conditions. Namely, since both picture naming and categorization require activation of visual semantic predicates, the expected delay in response time in the categorizethen-name condition should be reduced with respect to the delay observed in the corresponding condition with words.

\section{EXPERIMENT 2 Picture Naming}

\section{Method}

Participants. Eighty students at the University of Padua took part in the study and were equally distributed in the two experimental conditions (free naming and conditional naming). None had participated in the previous experiment. All had normal or corrected-tonormal vision.

Material and Procedure. The pictures corresponding to the 48 names in Experiment 1 were used. The naming agreement for the biological and artifact sets was balanced ( 90.83 vs. 86.36 , respectively) according to the rating provided by Dell' Acqua et al. (2000).

Table 1

Response Times in Milliseconds and Percentages of Error in Word Naming (Experiment 1) and Picture Naming (Experiment 2)

\begin{tabular}{lllllr}
\hline & \multicolumn{4}{c}{ Naming Condition } & \\
\cline { 2 - 5 } \multicolumn{1}{c}{ Task } & \multicolumn{2}{c}{ Free } & \multicolumn{2}{c}{ Conditional } & \\
\cline { 2 - 5 } \multicolumn{1}{c}{} & RT & PE & RT & PE & Difference \\
\hline Word naming & 493 & 0.0 & 702 & 0.7 & -209 \\
Picture naming & 808 & 5.4 & 807 & 4.8 & 1 \\
\hline
\end{tabular}


The pictures were presented as black lines on a light gray background. When projected, they subtended a visual angle of about $5^{\circ}$ horizontally $\times 4^{\circ}$ vertically.

The procedure was the same as in Experiment 1, except that the task in both the free and conditional conditions was now picture naming.

\section{Results and Discussion}

As in Experiment 1, half ( $n=20)$ of the participants in the free-naming condition served as controls for the biological conditional-naming condition, and for them, we considered only their performance on biological items. The remaining 20 participants served as controls for the artifact conditional-naming condition, and for them, we considered only their data for artifacts. Thus, all the data analyses reported will be based on 1,920 datapoints in each of the two experimental conditions.

Data from 168 trials were omitted due to failures of the voice key. RTs were subjected to the same trimming procedure as in Experiment 1. Seventy-five responses were outliers $(3.90 \%)$.

Mean RTs of correct responses and percentages of errors are reported in Table 1. The 1-msec difference between the two naming conditions is not significant.

The pattern of results shows that pictures-unlike words (see Experiment 1) - do not need extra time in the conditional- as compared with the free-naming task.

To test for the reliability of the difference between words and pictures in the two tasks, we performed an analysis of variance (ANOVA) with experiment (Experiment 1: words vs. Experiment 2: pictures) and condition (free vs. conditional naming) as between-subjects factors. The main effects of experiment $[F(1,136)=212.26]$ and condition $[F(1,136)=51.59]$, as well as the interaction $[F(1,136)=52.99]$ proved significant (all $p \mathrm{~s}<.001)$. As expected, the difference between the two naming conditions was significant for words but not for pictures.

Although the relevant comparison is that between free and conditional naming within each modality, it is interesting that in the conditional-naming condition, RTs (702 $\mathrm{msec}$ ) to words (Experiment 1) were significantly faster than RTs $(807 \mathrm{msec}$ ) to pictures (Experiment 2 ) [test of simple effect, $F(1,136)=26.57$ ]. This datum will be considered in the General Discussion section.

The lack of a difference in RTs between free and conditional naming for pictures is surprising, given the large literature on the cost of performing two tasks in the same trial. If picture categorization and naming are functionally distinct processes, one would expect that having to categorize an element before naming it would require more time than naming it without making a category decision. Since at least some of the stages of the two processes are distinct, we predicted a delay for the conditional naming of pictures, albeit reduced with respect to the delay for words. As it happens, the pattern for words is consistent with the dual-task paradigm (see Experiment 1) but the pattern for pictures is not.

The lack of a delay in the conditional naming of pictures is consistent with the claim that picture naming in the free- and conditional-naming conditions capitalizes on the same mental operations.

The pattern is congruent with Caramazza, Hillis, Rapp, \& Romani's (1990) proposal that picture naming involves retrieval of more detailed semantic information than does categorization. If indeed the semantic information required for naming includes all the information required by categorization, there should be no difference between conditional and free naming, the pattern we have actually found.

An alternative explanation would be that picture naming is much slower than reading aloud, possibly because of the higher uncertainty associated with retrieving the names of pictures, and thus it might allow other operations, such as categorization, to be carried out. If this were true, one would find no difference between conditional and free picture naming, even if the processing required for categorization was completely different from that required for naming.

Although congruent with the pattern we obtained, this explanation seems to us unlikely for two reasons. First, the name-agreement ratings for the pictures we used were quite high (88.64). Even when we excluded the two pictures with the lowest name-agreement ratings, thus having an agreement ratings of 91.37 , the RTs were numerically identical. Therefore, uncertainty by itself does not seem to be responsible for the pattern we obtained. Second, the claim that the processing required by picture categorization and naming are different must assume that either categorization does not require access to the semantic system and naming does, or vice versa. As for the first alternative, Snodgrass and McCullough (1986) have proposed that in categorizing pictures from visually dissimilar categories, a visual strategy that bypasses semantics might be used. However, subsequent studies have shown that access to the semantic system is required in those conditions also (Job et al., 1992; Lotto et al., 1999). As for the possibility that picture categorization requires access to the semantic system but picture naming does not, this seems unlikely (see Theios \& Amrhein, 1989).

\section{GENERAL DISCUSSION}

In this study, the participants were required to name pictures and words under two conditions: (1) All the items of the list had to be named, and (2) only the items belonging to a prespecified category had to be named. For pictures, there was no difference in the RTs between the free- and the conditional-naming conditions. For words, RTs in the conditional-naming condition were longer than in the free-naming condition.

This pattern invites the conclusion that to categorize a picture in order to name it does not require an extra processing step or that such an extra step is carried out at no cost to the naming process. However, for words, the processes of categorization and naming cannot be performed conjointly without a cost. 
Before discussing further the results, we should consider the issue of their reliability. Sholl (1996), in her doctoral dissertation, investigated bilinguals' performance in both L1 and L2 using, among others, the tasks of free and conditional naming of pictures. The pattern she obtained is very similar to ours: In the free-naming conditions, pictures of animate and inanimate items took 1,201 and $1,093 \mathrm{msec}$ to be responded to, respectively. In the conditional-naming conditions, the corresponding RTs were 1,135 for animate and 1,079 for inanimate items, the differences being not significant. Sholl did not discuss the implications of these findings, which were outside the scope of her work, but it is interesting to note that in her study also, conditional naming of pictures was not more costly than free naming of pictures.

Naming and categorization are complex cognitive operations that require one to access different kinds of representations. According to dual-route models (e.g., Coltheart, Rastle, Perry, Langdon, \& Ziegler, 2001), word naming can be accomplished by one of three procedures: a nonlexical route, a lexical nonsemantic route, or a semantic route. Word categorization, instead, always requires access to the semantic system. Access to the semantic system is also required for picture naming and for picture categorization (but see Snodgrass \& McCullough, 1986).

For words, all three possible procedures that are able to produce a phonological form are activated in parallel upon presentation of the stimulus, but their contribution to the activation of the phonological forms varies. In the free-naming condition, it may be assumed that-ceteris paribus - either the nonlexical or the lexical nonsemantic procedures will contribute more activation to the phonological level than will the semantic procedure because of the relatively slow rate of activation of semantic representations. In the conditional-naming condition, instead, the semantic system will contribute heavily to the activation of entries in the name-production system because of its involvement in the classification of the item as biological or artifact. Only after such classification will the picture label be available for production. Thus, in this case, the licensing conditions for picture-name production are determined by the semantic procedure, which then modulates the timing of phonological output.

For pictures, both free and conditional naming are performed through a procedure that activates information in the structural description system, in the semantic system, and in the name-production system. The same three levels of representations are involved in the two tasks, and hence-apart from the category decision in conditional naming - no processing difference should be expected. This is exactly what happened in Experiment 2, in which there was no difference in RTs between freeand conditional-picture naming. No cost at all for the category decision is surprising, yet it accords well with the assumption that picture categorization and naming share most processing stages.

On the assumption that category decisions require access to the semantic system, there are two possible loci at which the semantic system may exert its effects-that is, either before or after the name-retrieval stage. In the former case, information from the semantic system is used immediately to filter out the elements of the irrelevant category, so that only the names of the elements of the target category are retrieved and produced. In the latter case, information from the semantic system activates the name of each picture that the participants are presented with, so that the names of the elements of both the target and the nontarget categories are available for production. The selection mechanism would operate at this stage so that only the names of the target category elements are actually produced. At present, no data are available to decide this issue.

A further aspect of the data is worth considering. On the widely accepted assumption that access to the semantic system is faster for pictures than for words (Friedman \& Bourne, 1976; Potter \& Faulconer, 1975; Smith \& Magee, 1980), it may seem incongruent for conditional naming of words to be faster than conditional naming of pictures. However, this was the case: Conditional naming of words was about $100 \mathrm{msec}$ faster than conditional naming of pictures. However, the functional architecture of the dual-route model allows us to interpret this datum straightforwardly. In fact, because of the parallel activation of the three routes that mediate the print-to-phonology system, in word naming, the faster routes would preactivate lexical forms in the word-production system. This preactivation would then facilitate retrieval and production of the target word after the category decision has been made. However, for picture naming, the functional architecture prevents the possibility of preactivation of lexical forms other than from the semantic system.

In conclusion, the phenomenon we have reported here shows that word and picture naming can be accomplished through multiple, functionally distinguishable procedures. It also shows that the decision component about category membership for pictures is not costly in terms of accuracy and/or response time. Finally, such asymmetry between pictures and words in conditional versus free naming seems suitable for use in testing specific questions about the functional architecture of the human brain.

\section{REFERENCES}

Bortolini, U., Tagliavini, C., \& Zampolli, A. (1974). Lessico difrequenza della lingua italiana contemporanea. Milan: Garzanti.

Caramazza, A., Hillis, A. E., Rapp, B. C., \& Romani, C. (1990). The multiple semantic hypothesis: Multiple confusions? Cognitive Neuropsychology, 7, 161-189.

Coltheart, M. (1985). Cognitive neuropsychology and the study of reading. In M. I. Posner \& O. S. M. Marin (Eds.), Attention and performance XI (pp. 3-40). Hillsdale, NJ: Erlbaum.

Coltheart, M., Rastle, K., Perry, C., Langdon, R, \& Ziegler, J. (2001). DRC: A dual route and cascade model of visual word recognition and reading aloud. Psychological Review, 108, 204-256.

Dell'Acqua, R., Lotto, L., \& Job, R. (2000). Naming times and standardized norms for the Italian PD/DPSS set of 266 pictures: Direct comparisons with American, English, French, and Spanish published databases. Behavior Research Methods, Instruments, \& Computers, 32, 588-615. 
Friedman, A., \& Bourne, L. E. (1976). Encoding the levels of information in pictures and words. Journal of Experimental Psychology: General, 105, 169-190.

Joв, R, Rumiati, R, \& Lotтo, L. (1992). The picture superiority effect in categorization: Visual or semantic? Journal of Experimental Psychology: Learning, Memory, \& Cognition, 18, 1019-1028.

Lloyd-Jones, T. J., \& Humphreys, G. W. (1997). Categorizing chairs and naming pears: Category differences in object processing as a function of task and priming. Memory \& Cognition, 25, 606-624.

LotTo, L. (1996). Forme superficiali e rappresentazione profonda nell'elaborazione dei concetti. Verso un modello integrato. Unpublished doctoral dissertation, University of Padua.

Lотто, L., Jов, R., \& Rumiati, R. (1999). Visual effects in picture and word categorization. Memory \& Cognition, 27, 674-684.

MCCANN, R. S., \& BESNER, D. (1987). Reading pseudohomophones: Implications for models of pronunciation assembly and the locus of word-frequency effects in naming. Journal of Experimental Psychology: Human Perception \& Performance, 13, 14-24.

Morton, J., \& Patterson, K. E. (1980). A new attempt at interpretation, or an attempt at a new interpretation. In M. Coltheart, K. E. Patterson, \& J. Marshall (Eds.), Deep dyslexia (pp. 91-118). London: Routledge.

PASHLER, H. (1984). Processing stages in overlapping tasks: Evidence for a central bottleneck. Journal of Experimental Psychology: Human Perception \& Performance, 10, 358-377.

Potter, M. C., \& Faulconer, B. A. (1975). Time to understand pictures and words. Nature, 253, 437-438.
Rapp, B. C., \& Caramazza, A. (1991). Cognitive neuropsychology: From impaired performance to normal cognitive structure. In R. G. Lister \& H. J. Weingartner (Eds.), Perspectives on cognitive neurosciences (pp. 384-404). New York: Oxford University Press.

SHoll, A (1996). Animacy effects in picture naming and bilingual translation: Perceptual and semantic contributionsto concept mediation. Unpublished doctoral dissertation, University of Massachusetts, Amherst.

Smith, M. C., \& Magee, L. E (1980). Tracing the time course of pictureword processing. Journal of Experimental Psychology: General, 109, 373-392.

Snodgrass, J. G., \& McCullough, B. (1986). The role of visual similarity in picture categorization. Journal of Experimental Psychology: Learning, Memory, \& Cognition, 12, 147-154.

Strain, E. S., Patterson, K., \& Seidenberg, M. S. (1995). Semantic effects in single-word naming. Journal of Experimental Psychology: Learning, Memory, \& Cognition, 21, 1140-1154.

Theios, J., \& Amrhein, P. C. (1989). Theoretical analysis of the cognitive processing of lexical and pictorial stimuli: Reading, naming, and visual and conceptual comparisons. Psychological Review, 96, 5-24.

\section{NOTE}

1. Snodgrass and McCullough (1986) argue that picture categorization can be accomplished on the basis of a relatively low-level visual strategy, provided the elements to be categorized belong to structurally dissimilar categories.

\section{APPENDIX \\ Stimuli From Biological (Left-Hand Columns) and Nonbiological (Right-Hand Columns) Categories in Experiments 1 and 2}

\begin{tabular}{llll}
\hline anguria & watermelon & amaca & hammock \\
arancia & orange & armadio & wardrobe \\
cammello & camel & camion & truck \\
canguro & kangaroo & cannone & cannon \\
carciofo & artichoke & carrozza & carriage \\
carota & carrot & cassetto & drawer \\
castagna & chestnut & cestino & basket \\
cigno & swan & cintura & belt \\
ciliegia & cherry & coltello & knife \\
elefante & elephant & elicottero & helicopter \\
fungo & mushroom & fucile & rifle \\
gallina & hen & gondola & gondola \\
gatto & cat & gonna & skirt \\
gufo & owl & guanto & glove \\
limone & lemon & libreria & bookshelf \\
pavone & peacock & panca & bench \\
peperone & pepper & pantofola & slipper \\
pera & pear & pigiama & pajamas \\
pinguino & penguin & pistola & pistol \\
piselli & peas & pugnale & dagger \\
sedano & celery & spada & sword \\
struzzo & ostrich & stivale & boot \\
tigre & tiger & treno & train \\
zebra & zebra & zattera & raft \\
\hline
\end{tabular}

(Manuscript received April 3, 2001;

revision accepted for publication January 16, 2002.) 